\title{
STUDI BEBERAPA PARAMETER EKONOMI SEBAGAI TOLOK UKUR PENGARUH PENELITIAN PENGEMBANGAN SISTEM USAHA TANI MINAPADI \\ (Studi Kasus di Desa Nanggerang, Kecamatan Binong, Kabupaten Subang)

\author{
Mohammad Noor ${ }^{*}$ dan Khaidir Ahmady Us ${ }^{* *}$
}

\begin{abstract}
ABSTRAK
Penelitian pengembangan sistem usaha tani minapadi telah dilakukan. Metode yang digunakan adalah metode survai dengan pendekatan Zero-One Relationship Approach, yaitu membagi petani terpilih dalam dua kelompok, yaitu kelompok petani yang dibina (cooperator) dan kelompok petani yang tidak dibina tetapi dipantau kegiatan sistem usaha taninya (non cooperator). Pengambilan sampel dilakukan secara acak sederhana, dengan jumlah petani responden terpilih sebanyak 22 orang petani koperator, 22 orang petani nonkoperator dan 8 orang petani biasa.

Hasil penelitian menunjukkan bahwa dari tahun 1989/1990 sampai dengan tahun 1992/1993 masukan pupuk terendah diperoleh pada petani koperator dan masukan pestisida tertinggi dicapai pada petani biasa. Alokasi tenaga kerja terbesar dalam aktivitas pertanian adalah pada petani biasa, yaitu masing-masing $1.836 \mathrm{jam} / \mathrm{ha} / \mathrm{tahun}$ (1989/1990); $2.256 \mathrm{jam} / \mathrm{ha} / \mathrm{tahun}$ (1990/ 1991); dan $2.084 \mathrm{jam} / \mathrm{ha} /$ tahun (1992/1993). Sedangkan pendapatan bersih terbesar diperoleh pada petani koperator, yaitu masing-masing Rp 2.090.102,- (1989/1990); Rp 1.407.295,- (1990/ 1991); dan Rp 3.584.257,- (1992/1993).
\end{abstract}

ABSTRACT: Study on the development of the economic pattern on the paddy-fish culture (Case study in the village of Nanggerang, Binong, Subang Regency). By: Mohammad Noor dan Khaidir Ahmady Us.

Studies on the development of the agribusiness system on the paddy fish culture had been carried out using survey method with zero-one Relationship Approach, where selected farmers were divided into two groups as: (1) guided farmer group (cooperator) and (2) non-guided but monitored farmer group (non-cooperator). The sampling method was simple random with 22 person cooperators and 22 non-cooperators, and 8 person ordinary farmers taken as respondents. The result showed that from $1989 / 1990$ to $1992 / 1993$ the lowest fertilizer input was reached by the cooperators while the highest pesticide input was reached by the ordinary farmers.

The ordinary farmers also allocated the highest labor in their activity. In 1989/1990 it was 1,836 hours/ha/year, becoming 2,256 hours/ha/year in 1990/1991 and 2,084 hours/ha/year in $1992 / 1993$.

The highest net revenue was achieved by the cooperators, which was Rp 2,090,102 in 1989/1990; $R p 1,407,295$ in 1991/1992; and Rp 3,584,257 in 1992/1993.

KEYWORDS: Economic pattern; rice fish culture; development; farming system.

\section{PENDAHULUAN}

Sistem usaha tani minapadi secara tradisional telah lama dipraktekkan di Indonesia, yaitu sekitar pertengahan abad ke-19. Tetapi perkembangan yang pesat tampak pada dekade delapan puluhan. Hal ini karena terjadinya persaingan yang ketat antara sektor pertanian dan nonpertanian dalam penggunaan lahan. Untuk itu mulai dari awal Pelita V dilakukanlah usaha terobosan agar swasembada pangan dan pembangunan pertanian dapat dilanjutkan, yaitu melalui usaha diversifikasi yang merupakan andalan utama pada Pelita IV.

\footnotetext{
Peneliti pada Balai Penelitian Perikanan Laut, Jakarta

**) Peneliti pada Balai Pengkajian dan Teknologi Pertanian Sukarami
} 
Salah satu usaha diversifikasi ini adalah penerapan sistem usaha tani minapadi yang kegiatan penelitiannya telah dilaksanakan dari tahun 1987-1989 di Desa Nanggerang, Kecamatan Binong, Kabupaten Subang oleh Puslitbang Tanaman Pangan. Ternyata sistem usaha tani minapadi dapat meningkatkan produksi padi sampai $14 \%$ pada jarak tanam $23 \mathrm{~cm} \times 23 \mathrm{~cm}$ atau $30 \mathrm{~cm} \times 15 \mathrm{~cm}$ dengan kepadatan ikan antara 2.500 sampai 3.500 ekor/ha (Sabri et al. dalam Oka et al., 1992) dan total pendapatan pada sistem usaha tani minapadi ini mencapai $1,5 \mathrm{kali}$ lipat dibandingkan dari hasil padinya (Oka et al., 1992).

Untuk mencapai keberhasilan pengembangan di suatu daerah sentra produksi diperlukan keterkaitan berbagai faktor penentu seperti: (1) kebijaksanaan dan komitmen pemerintah; (2) dukungan eksternal; (3) kondisi sosial-ekonomi yang mempengaruhi motivasi dan partisipasi petani serta pengguna lain; dan (4) teknologi maju yang spesifik sesuai dengan keragaan agroekosistem setempat (Manwan dan Oka,1990). Adapun ukuran keberhasilan suatu sistem usaha tani yang dilakukan melalui penelitian pengem bangan bagi petani, salah satunya adalah sampai sejauh mana suatu teknologi sistem produksi itu mampu meningkatkan kesejahteraan petani yang dapat dilihat dari pendapatan bersih yang diperoleh.

\section{Tujuan Penelitian}

Penelitian bertujuan untuk mendapatkan gambaran dan informasi mengenai dampak kegiatan penelitian pengembangan sistem usaha tani minapadi yang telah dilaksanakan antara tahun 1987-1989 terhadap masukan pupuk, pestisida dan tenaga kerja serta pendapatan bersih yang diperoleh oleh para petani.

\section{METODE PENELITIAN}

Penelitian dilakukan dengan metode survai. Penarikan sampel dilakukan secara acak sederhana. Petani sampel terdiri atas 3 kelompok, yaitu kelompok petani koperator, kelompok petani nonkoperator dan kelompok petani biasa.

Petani koperator adalah petani yang dibina dalam penelitian pengembangan. Petani nonkoperator adalah petani yang tidak dibina tetapi dipantau usaha tani minapadinya. Petani biasa adalah petani yang tidak dibina dan tidak dipantau usaha tani minapadi dalam penelitian pengembangan. Jumlah responden yang diambil sebanyak 22 orang petani koperator, 22 orang petani nonkoperator dan 8 orang petani biasa.

Data primer diperoleh melalui wawancara semistruktur. Sedangkan data sekunder diperoleh melalui wawancara bebas dengan berbagai pihak yang terkait dalam kegiatan sistem usaha tani minapadi.

Untuk memperoleh gambaran yang jelas dari keberhasilan pengembangan sistem usaha tani minapadi, dilakukan analisis perbandingan masukan per hektar pupuk pestisida dan tenaga kerja serta penerimaan bersih yang didasarkan pada penerimaan padi, penerimaan ikan, penerimaan kotor, biaya sarana produksi, biaya tenaga, biaya total antara petani koperator, petani nonkoperator dan petani biasa serta dilakukan uji banding dengan hasil yang diperoleh terdahulu dan diuraikan secara deskriptif.

Penelitian ini dilaksanakan pada tanggal 6-13 Mei 1993 di Desa Nanggerang, Kecamatan Binong, Kabupaten Subang, Jawa Barat.

\section{HASIL DAN PEMBAHASAN}

\section{Karakteristik Wilayah dan Penelitian Lahan}

Desa Nanggerang mempunyai luas areal sekitar 414,558 ha yang terdiri atas sawah teknis 292,340 ha, sawah setengah teknis 17,930 ha, tanah darat 98,248 ha dan kolam atau empang seluas 6,00 ha. Untuk sawah teknis dan setengah teknis dikelola oleh 785 orang petani pemilik dan 544 orang petani penggarap. Pengairan untuk sawah teknis sepanjang tahun yang berasal dari dam Cimacan, Jatiluhur. Prasarana pengairan terdiri atas saluran primer 9 buah, sekunder 9 buah, tertier 15 buah dan saluran kuarter 49 buah serta pintu pembagi air sebanyak 32 buah.

Umumnya seluruh petani koperator memiliki lahan sawah garapan seluas antara 0,28 sampai 2,0 ha. Petani nonkoperator relatif lebih rendah, yaitu antara 0,14 sampai 1,0 ha. Sedangkan untuk petani biasa lahan garapan yang mereka miliki relatif lebih luas dari petani nonkoperator, yaitu antara 0,5 ha sampai 1,25 ha. 


\section{Pola Tanam}

Pola tanam yang dilaksanakan di Desa Nanggerang adalah hasil kajian dari Balai Penelitian Tanaman Pangan Sukamandi, yaitu mina padi-ikan (penyelang)-minapadi-palawija-ikan.

\section{Tingkat Pemakaian Masukan}

Tingkat pemakaian masukan yang digunakan oleh petani koperator, nonkoperator dan petani biasa untuk musim tanam (MT) 1992/1993 disajikan pada Tabel 1.

Dari Tabel 1 terlihat bahwa pemakaian benih padi, urea, TSP, insektisida yang terkecil diperoleh petani koperator. Sedangkan masukan yang tertinggi untuk benih, insektisida, herbisida dan furadan diperoleh petani biasa. Secara umum pemakaian pupuk terendah dicapai oleh petani nonkoperator, yaitu $781 \mathrm{~kg}$, sedangkan pemakaian pestisida tertinggi oleh petani biasa.

Rendahnya pemakaian pupuk pada petani koperator ini karena adanya korelasi ekologis antara penanaman ikan dengan peningkatan kesuburan sawah, di mana kotoran-kotoran daripada ikan dan makanan yang tidak termakan akan menjadi pupuk bagi tanah dan air yang secara alamiah telah diketahui oleh petani koperator, sehingga mereka menerapkan pemakaian pupuk yang lebih rendah dari pada petani nonkoperator dan biasa. Fagi et al. (1991) mengemukakan bahwa dengan minapadi, penggunaan pupuk akan lebih rendah dari pemupukan padi tanpa perlakuan ikan.

Selanjutnya pemakaian pestisida yang tinggi pada petani biasa disebabkan karena serangan hama yang lebih tinggi dibandingkan dengan petani koperator dan nonkoperator. Serangan hama yang tinggi disebabkan tidak terjadinya keseimbangan secara ekologis pada ekosistem sawah petani biasa. Sedang pada sawah petani koperator dan nonkoperator ada hubungan antara ikan, padi, air dan tanah sehingga tercapai keseimbangan ekosistem yang baik.

Untuk mengevaluasi adopsi teknologi sistem usaha tani minapadi ini, pencapaian dilaksanakan perbandingan tingkat masukan antara MT 1992/1993 dengan MT 1989/1990 dan 1990/1991 yang dapat dilihat pada Tabel 2 dan Tabel 3.

Tabel 1. Tingkat pemakaian masukan per hektar yang digunakan oleh petani koperator, nonkoperator dan petani biasa pada MT 1992/1993.

Table 1. Input per ha used by cooperator, non-cooperator, and ordinary farmers, in 1992/1993 crop season.

\begin{tabular}{lrccc}
\hline \multicolumn{1}{c}{$\begin{array}{c}\text { Jenis masukan } \\
\text { Input }\end{array}$} & & $\begin{array}{c}\text { Koperator } \\
\text { Cooperator }\end{array}$ & $\begin{array}{c}\text { Nonkoperator } \\
\text { Non-cooperator }\end{array}$ & $\begin{array}{c}\text { Petani biasa } \\
\text { Ordinary farmers }\end{array}$ \\
\hline Benih padi (Rice seed) & $\mathrm{kg}$ & 55.0 & 67.14 & 69 \\
Benih ikan (Fish fry) & ekor/tail & 64.3 & 39.32 & 0 \\
Pakan (Feed) & $\mathrm{kg}$ & 190.5 & 129.26 & 0 \\
Urea & $\mathrm{kg}$ & 400.0 & 544.0 & 420 \\
TSP & $\mathrm{kg}$ & 236.0 & 575.2 & 250 \\
KCl & $\mathrm{kg}$ & 145.2 & 67.4 & 121 \\
Za & $\mathrm{kg}$ & - & - & - \\
Insektisida (Insecticide) & $\mathrm{L}$ & 2.45 & 3.0 & 3.4 \\
Herbisida (Herbicide) & $\mathrm{L}$ & 1.88 & 1.82 & 2.6 \\
Furadan (Furadan) & $\mathrm{L}$ & 25.14 & 12.30 & 28.6 \\
\hline
\end{tabular}

Sumber (Source): Data primer (Primary data) 
Tabel 2. Tingkat pemakaian masukan per hektar yang digunakan oleh petani koperator, nonkoperator dan petani biasa pada MT 1989/1990 dan 1990/1991.

Table 2. Inputs per ha used by cooperator, non-cooperator and ordinary farmer in 1989/1990 and 1990/1991 crop seasons.

\begin{tabular}{|c|c|c|c|c|c|c|c|}
\hline \multicolumn{2}{|l|}{$\begin{array}{l}\text { Jenis masukan } \\
\text { Inputs }\end{array}$} & \multicolumn{2}{|c|}{$\begin{array}{l}\text { Koperator } \\
\text { Cooperator }\end{array}$} & \multicolumn{2}{|c|}{$\begin{array}{l}\text { Nonkoperator } \\
\text { Non-cooperator }\end{array}$} & \multicolumn{2}{|c|}{$\begin{array}{c}\text { Petani biasa } \\
\text { Ordinary farmers }\end{array}$} \\
\hline & & $1989 / 1990$ & $1990 / 1991$ & $1989 / 1990$ & 1990/1991 & 1989/1990 & 1990/1991 \\
\hline Benih padi (Rice seed) & kg & 65.90 & 64.00 & 61.06 & 60.00 & 57.80 & 62.00 \\
\hline Benih ikan (Fish fry) & ekor (tail) & $1,123,954$ & 129,200 & - & $\cdot$ & - & - \\
\hline Pakan (Feed) & $\mathbf{k g}$ & 19.29 & 8.00 & . & - & - & . \\
\hline Urea & $\mathrm{kg}$ & 384.70 & 386.00 & 408.70 & 429.60 & 374.80 & 370.10 \\
\hline TSP & $\mathbf{k g}$ & 306.10 & 293.50 & 296.80 & 379.60 & 432.30 & 360.80 \\
\hline $\mathrm{KCl}$ & kg & 58.00 & 110.00 & 64.00 & 84.00 & 64.00 & 155.00 \\
\hline $\mathrm{Za}$ & kg & $\cdot$ & 7.40 & - & 47.00 & 13.37 & 104.00 \\
\hline Pupuk (Fertilizer) & $L$ & 0.06 & 0.17 & 0.12 & - & 0.23 & 2.96 \\
\hline Karbofuran (Carbofuran) & $\mathrm{L}$ & 12.75 & 21.24 & 20.45 & 19.11 & 22.23 & 29.10 \\
\hline Herbisida (Herbicide) & $\mathbf{L}$ & 0.25 & 0.36 & 0.11 & 0.62 & 1.06 & 0.64 \\
\hline Rodentisida (Rodenticide) & $\mathrm{L}$ & 1.83 & 3.55 & 2.76 & 4.17 & 3.92 & 3.88 \\
\hline Insektisida (Insecticide) & L & 1.65 & 2.24 & 1.91 & 2.51 & 2.70 & 3.24 \\
\hline
\end{tabular}

Sumber (Source): Oka et al., 1992.

Tabel 3. Perbandingan tingkat pemakaian masukan per hektar untuk pupuk dan pestisida yang digunakan oleh petani koperator, nonkoperator dan petani biasa pada MT 1980/1990; MT 1990/1991; dan MT 1992/1993.

Table 3. The comparison of input rates of fertilizer and pesticide per ha used by the cooperator, noncooperator and ordinary farmers during 1989/1990; 1990/1991; and 1992/1993 crop seasons.

\begin{tabular}{lrrrr}
\hline \multicolumn{1}{c}{$\begin{array}{c}\text { Jenis masukan } \\
\text { Inputs }\end{array}$} & Koperator & $\begin{array}{c}\text { Nonkoperator } \\
\text { Cooperator }\end{array}$ & $\begin{array}{c}\text { Petani biasa } \\
\text { Non-cooperator }\end{array}$ & \begin{tabular}{c} 
Ordinary \\
\hline MT 1989/1990 (1989/1990 crop season)
\end{tabular} \\
- Pupuk (Fertilizer) & $\mathrm{kg}$ & 748.86 & 769.62 & \\
- Pestisida (Pesticide) & $\mathrm{L}$ & 16.18 & 25.23 & 29.91 \\
MT 1990/1991 (1990/1991 crop season) & & & & \\
- Pupuk (Fertilizer) & $\mathrm{kg}$ & 797.57 & 940.70 & 992.88 \\
- Pestisida (Pesticide) & $\mathrm{L}$ & 27.39 & 26.41 & 36.86 \\
MT 1992/1993(1992/1993 crop season) & & & & \\
- Pupuk (Fertilizer) & $\mathrm{kg}$ & 781.20 & 886.60 & 791.00 \\
- Pestisida (Pesticide) & $\mathrm{L}$ & 29.56 & 17.12 & 34.60 \\
\hline
\end{tabular}

Sumber (Source): Data primer (Primary data) 
Berdasarkan Tabel 2 dan Tabel 3 jelaslah bahwa pemakaian pupuk terendah tahun 1989/ 1990 sampai dengan tahun 1992/1993 diperoleh petani koperator dan pemakaian pestisida tertinggi didapat pada petani biasa. Oka et al. (1992) mengemukakan bahwa sistem usaha tani minapadi mengurangi pemakaian insektisida maupun populasi rumput. Hal ini karena terciptanya hubungan yang harmonis antara padi, ikan, air dan tanah sehingga tercapai kondisi keseimbangan ekologis yang baik, sehingga dengan demikian serangan hama dan rumput menjadi berkurang.

\section{Tenaga Kerja}

Kebutuhan tenaga kerja dalam jam per hektar antara petani koperator, nonkoperator dan petani biasa tahun 1989/1990; 1990/1991; dan 1992/1993 dapat dilihat pada Tabel 4 dan Tabel 5 .

Secara umum berdasarkan Tabel 4 dan Tabel 5 terlihat bahwa alokasi tenaga kerja dalam aktivitas pertanian yang terbesar adalah pada petani biasa, yaitu masing-masing $1.836 \mathrm{jam} / \mathrm{ha} /$ tahun (1989/1990), $2.256 \mathrm{jam} / \mathrm{ha} / \mathrm{tahun} \mathrm{(1990/}$ 1991) dan $2.084 \mathrm{jam} / \mathrm{ha} /$ tahun (1992/1993).

Hal ini terjadi karena alokasi tenaga kerja untuk memupuk, menyiang dan menyemprot pada petani biasa lebih tinggi dibanding petani koperator dan nonkoperator. Petani yang melakukan sistem usaha minapadi akan sering ke lapangan sehingga serangan hama diketahui lebih dini. Selain itu sistem usaha tani minapadi menciptakan keseimbangan ekologis yang baik pada ekosistemnya, sehingga dengan demikian serangan hama berkurang seperti telah diuraikan di atas. Berbeda pada petani biasa mereka melakukan monitoring hanya pada waktu-waktu tertentu saja. Oleh karena pada sistem usaha tani minapadi pemakaian pestisida lebih sedikit dan bahkan mungkin juga tidak menggunakan sama sekali, maka dengan demi-kian akan mengurangi kebutuhan tenaga kerja untuk penyiangan dan penyemprotan (Syamsiah et al., 1992). Demikian juga dengan penggunan pupuk pada sistem usaha tani minapadi jauh lebih kecil dibanding petani biasa, seperti telah diuraikan di atas, karenanya kebutuhan tenaga kerja untuk pemupukan juga berkurang.

Tabel 4. Alokasi tenaga kerja dalam aktivitas pertanian pada MT 1989/1990 dan 1990/1991 per ha/tahun.

Table 4. The allocation of labor on farmer activity per ha per years in 1989/1990 and 1990/1991.

\begin{tabular}{|c|c|c|c|c|c|c|}
\hline \multirow[t]{2}{*}{$\begin{array}{l}\text { Kegiatan } \\
\text { Activities }\end{array}$} & \multicolumn{2}{|c|}{$\begin{array}{l}\text { Koperator } \\
\text { Cooperator }\end{array}$} & \multicolumn{2}{|c|}{$\begin{array}{l}\text { Nonkoperator } \\
\text { Non-cooperator }\end{array}$} & \multicolumn{2}{|c|}{$\begin{array}{c}\text { Petani biasa } \\
\text { Ordinary farmers }\end{array}$} \\
\hline & $1989 / 1990$ & $1990 / 1991$ & $1989 / 1990$ & 1990/1991 & $1989 / 1990$ & $1990 / 1991$ \\
\hline Persiapan lahan (Land preparation) & 43 & 474 & 445 & 316 & 553 & 357 \\
\hline Menyemai (Seedling) & 58 & 73 & 63 & 48 & 58 & 43 \\
\hline Mengairi (Irrigating) & 64 & 93 & 60 & 82 & 61 & 78 \\
\hline Tanam padi (Rice stoccking) & 190 & 426 & 168 & 213 & 240 & 382 \\
\hline Tanam ikan (Fish stocking) & 9 & 24 & - & - & - & - \\
\hline Pembasmian tikus (Eradication) & 97 & 90 & 99 & 74 & 87 & 91 \\
\hline Memupuk (Fertilizing) & 48 & 76 & 49 & 47 & 53 & 56 \\
\hline Menyiang (Weeding) & 123 & 154 & 151 & 135 & 169 & 255 \\
\hline Panen ikan (Fish harvesting) & 24 & 61 & - & - & - & - \\
\hline Menyemprot (Spraying) & 28 & 50 & 51 & 58 & 51 & 60 \\
\hline Panen padi (Rice harvesting) & 428 & 927 & 377 & 627 & 529 & 893 \\
\hline Pascapanen (Post harvesting) & 21 & 61 & 26 & 15 & 37 & 43 \\
\hline $\begin{array}{r}\text { jam/ha/tahun } \\
\text { (hours/ha/years) }\end{array}$ & 1.533 & 2,609 & 1,488 & 1,625 & 1,836 & 2,256 \\
\hline
\end{tabular}

Sumber (Source) : Oka et al., 1992. 
Tabel 5. Alokasi tenaga kerja dalam aktivitas pertanian pada MT 1992/1993 per ha/tahun. Table 5. Allocation of labor on farmer activity per ha per year in 1992/1993.

\begin{tabular}{lccc}
\hline \multicolumn{1}{c}{$\begin{array}{c}\text { Kegiatan } \\
\text { Acitivities }\end{array}$} & $\begin{array}{c}\text { Koperator } \\
\text { Cooperator }\end{array}$ & $\begin{array}{c}\text { Nonkoperator } \\
\text { Non-cooperator }\end{array}$ & $\begin{array}{c}\text { Petani biasa } \\
\text { Ordinary farmers }\end{array}$ \\
\hline Persiapan lahan (Land preparation) & 491 & 540 & 355 \\
Menyemai (Seedling) & 64 & 57 & 41 \\
Mengairi (Irrigating) & 121 & 36 & 72 \\
Tanam padi (Rice stocking) & 340 & 329 & 359 \\
Tanam ikan (Fish stocking) & 111 & 65 & - \\
Memupuk (Fertilizing) & 44 & 46 & 56 \\
Menyiang (Weeding) & 111 & 93 & 302 \\
Panen ikan (Fish harvesting) & 80 & 66 & - \\
Menyemprot (Spraying) & 38 & 28 & 53 \\
Panen padi (Rice harvesting) & 523 & 433 & 808 \\
Pascapanen (Post harvesting) & 25 & 13 & 38 \\
\hline Total jam/ha/thn (hours/ha/yrs) & 1,918 & 1,706 & 2,084 \\
\hline
\end{tabular}

Sumber (Source): Data primer (Primary data)

Dari Tabel 4 dan Tabel 5 juga terlihat bahwa alokasi tenaga kerja terendah adalah pada petani nonkoperator, yaitu $1488 \mathrm{jam} / \mathrm{ha} /$ tahun (1989/ 1990), $1625 \mathrm{jam} / \mathrm{ha} / \mathrm{tahun}(1990 / 1991)$ dan 1.706 $\mathrm{jam} / \mathrm{ha} /$ tahun (1992/1993). Hal ini karena, walaupun adopsi teknologi sudah berjalan dengan baik pada petani nonkoperator, akan tetapi intensitas penanaman ikan belum seperti petani koperator. Ini jelas terlihat pada alokasi tenaga kerja untuk mengairi, menanam ikan dan panen ikan dari tahun 1989/1990 sampai dengan 1992/1993 petani koperator jauh lebih tinggi daripada petani nonkoperator.

Khusus untuk petani koperator terlihat bahwa terjadi lonjakan alokasi tenaga kerja untuk mengairi, menanam ikan, panen ikan dari tahun 1989/1990 sampai dengan 1992/1993, yaitu dari $64 \mathrm{jam} / \mathrm{ha} /$ tahun (1989/1990) untuk mengairi menjadi $121 \mathrm{jam} / \mathrm{ha} /$ tahun (1992/1993); tanam ikan dari 9 jam/ha/tahun (1989/1990) menjadi 111 $\mathrm{jam} / \mathrm{ha} /$ tahun (1992/1993); serta untuk panen ikan dari 24 jam/ha/tahun (1989/1990) menjadi 80 $\mathrm{jam} / \mathrm{ha} /$ tahun (1992/1993), atau terjadi peningkatan dari tahun 1989/1990 ke tahun 1992/1993 sebesar $89,06 \%$ untuk mengairi; $133,33 \%$ untuk tanam ikan; dan untuk panen ikan sebesar $233,33 \%$.

Lonjakan alokasi tenaga kerja ini terjadi karena adanya perubahan di dalam pola usaha produksi di mana petani menyesuaikan pola usaha produksi terhadap permintaan pasar. Pada pola usaha produksi yang lama, ukuran ikan yang ditanam adalah benih ukuran $3-5 \mathrm{~cm}$ (ngaramo, fingerling) dengan padat penebaran antara 2.500-3.000 ekor/ha. Lama pemeliharaan antara 2-3 bulan sehingga sudah siap dipanen sebagai ikan konsumsi atau sebagai benih untuk dibesarkan pada sistem budidaya keramba jaring apung di Waduk Cirata, Jatiluhur dan Saguling serta untuk benih budidaya ikan kolam air deras (Oka et al., 1992). Sedangkan yang saat ini dilaksanakan oleh petani setelah penebaran ikan mulai dari ukuran benih postlarva I (kebul) yang dalam satu liter berisi antara 5.000-6.000 ekor benih, dengan masa pemeliharaan $20 \mathrm{~s} / \mathrm{d} 23$ hari dapat dipanen dengan menghasilkan benih ukuran $3-5 \mathrm{~cm}$. Dengan singkatnya waktu pemeliharaan, maka dapat diproduksi benih ukuran 3-5 $\mathrm{cm}$ dalam satu musim tanam padi baik itu musim kemarau (musim gadu) maupun musim peng- 
hujan (musim rendeng) sebanyak 2 kali. Demikian juga pada musim penyelang dapat ditanam ikan satu kali. Sedang pada musim palawija dapat menanam 2 sampai 5 kali. Dengan demikian jelas hal ini menyebabkan terjadinya lonjakan alokasi tenaga kerja untuk mengairi, menanam ikan dan panen ikan.

Dari urâian di atas dapat ditarik kesimpulan bahwa ternyata petani di Desa Nanggerang cukup mudah dalam mengadopsi teknologi dan mereka juga cepat tanggap dan luwes di dalam menghadapi perubahan dan permintaan pasar, serta tidak kaku di dalam menerapkan paket teknologi sistem usaha tani.

\section{Analisis Finansial}

Analisis finansial petani koperator, nonkoperator dan petani biasa dari MT 1989/1990, MT 1990/1991 dan M'T 1992/1993 disajikan pada Table 6 dan Tabel 7.

Dari Tabel 6 dan Tabel 7 diketahui bahwa penerimaan bersih terbesar dari tahun 1989/1990 sampai dengan MT 1992/1993, diperoleh petani koperator sedangkan yang terendah diperoleh petani biasa. Rata-rata penerimaan bersih per bulan untuk MT 1992/1993 bagi petani koperator adalah Rp 298.688,08/bulan, nonkoperator $\mathrm{Rp}$ $225.843,58 /$ bulan dan petani biasa $R p 94.556,58 /$ bulan. Sedangkan persentase peningkatan pendapatan bersih petani koperator dari MT 1989/ 1990 ke MT 1992/1993 adalah sebesar 71,49\%. Peningkatan yang besar dari pendapatan bersih petani koperator ini disebabkan adanya perubahan pola produksi ikan dalam sistem usaha tani minapadi akibat perubahan permintaan pasar dari kebutuhan benih ukuran 75-100 g/ekor untuk pembesaran budidaya ikan dalam keramba, jaring apung maupun kolam air deras menjadi benih ukuran 40-60 ekor/kg (25-16,67 g), seperti telah diuraikan terdahulu. Selanjutnya untuk petani nonkoperator tahun 1992/1993 terjadi peningkatan sebesar $\mathrm{Rp}$ 1.892.499,$(231,47 \%)$ jika dibandingkan tahun 1990/1991. Peningkatan pada petani nonkoperator ini pada MT 1992/1993 karena petani nonkoperator juga mengantisipasi perubahan permintaan pasar, akan tetapi dalam intensitas penanaman ikan yang lebih rendah dibanding petani koperator.

Tabel 6. Total pendapatan ( $\mathrm{Rp}$ ) per hektar per tahun petani koperator, nonkoperator dan petani biasa di Desa Nanggerang MT 1989/1990 dan 1990/1991.

Table 6. Total income (Rp) per ha of cooperator, non-cooperator and ordinary farmers per year in Nanggerang in 1989/1990 and 1990/1991 crop seasons.

\begin{tabular}{|c|c|c|c|c|c|c|}
\hline \multirow[t]{2}{*}{$\begin{array}{l}\text { Komponen } \\
\text { Component }\end{array}$} & \multicolumn{2}{|c|}{$\begin{array}{l}\text { Koperator } \\
\text { Cooperator }\end{array}$} & \multicolumn{2}{|c|}{$\begin{array}{l}\text { Nonkoperator } \\
\text { Non-cooperator }\end{array}$} & \multicolumn{2}{|c|}{$\begin{array}{c}\text { Petani biasa } \\
\text { Ordinary farmers }\end{array}$} \\
\hline & $1989 / 1990$ & 1990/1991 & 1989/1990 & 1990/1991 & 1989/1990 & 1990/1991 \\
\hline $\begin{array}{l}\text { Penerimaan padi } \\
\text { Rice income }\end{array}$ & $3,152,070$ & $2,648,300$ & $2,730,600$ & $2,498,920$ & $2,328,360$ & $2,253,715$ \\
\hline $\begin{array}{l}\text { Penerimaan ikan } \\
\text { Fish income }\end{array}$ & 369,470 & 743,625 & 0 & 0 & 0 & 0 \\
\hline $\begin{array}{l}\text { Penerimaan kotor } \\
\text { Gross revenues }\end{array}$ & $3,521,540$ & $3,391,925$ & $2,730,600$ & $2,498,920$ & $2,328,360$ & $2,2543,715$ \\
\hline $\begin{array}{l}\text { Biaya sarana produksi } \\
\text { Production facilities costs }\end{array}$ & 382,331 & 658,850 & 259,494 & 582,523 & 309,153 & 444,637 \\
\hline $\begin{array}{l}\text { Biaya tenaga kerja } \\
\text { Cost of labor }\end{array}$ & $1,049,107$ & $1,325,780$ & 958,759 & $1,098,780$ & 916,064 & $1,058,600$ \\
\hline $\begin{array}{l}\text { Total biaya } \\
\text { Total costs }\end{array}$ & $1,431,438$ & $1,984,630$ & $1,218,253$ & $1,681,303$ & $1,225,217$ & $1,503,237$ \\
\hline $\begin{array}{l}\text { Penerimaan bersih } \\
\text { Net income }\end{array}$ & $2,090,102$ & $1,407,295$ & $1,512,347$ & 817,617 & $1,103,143$ & 750,478 \\
\hline
\end{tabular}


Tabel 7. Total pendapatan ( $\mathrm{Rp}$ ) per hektar per tahun petani koperator, nonkoperator dan petani biasa di Desa Nanggerang pada MT 1991/1992.

Table 7. Total income $(R p)$ cooperator, non-cooperator and ordinary farmers in Nanggerang village in $1991 / 1992$ crop season.

\begin{tabular}{lccr}
\hline \multicolumn{1}{c}{$\begin{array}{c}\text { Komponen } \\
\text { Component }\end{array}$} & $\begin{array}{c}\text { Koperator } \\
\text { Cooperator }\end{array}$ & $\begin{array}{c}\text { Nonkoperator } \\
\text { Non-cooperator }\end{array}$ & $\begin{array}{c}\text { Petani biasa } \\
\text { Ordinary farmers }\end{array}$ \\
\hline Penerimaan padi (Rice income) & $2,634,722$ & $2,653,505$ & $2,417,644$ \\
Penerimaan ikan (Fish income) & $2,884,612$ & $1,481,518$ & 0 \\
Penerimaan kotor (Gross revenues) & $5,519,334$ & $4,135,023$ & $2,417,649$ \\
Biaya sarana produksi (Production & 931,492 & 517,482 & 296,050 \\
facilities cost) & & & \\
Biaya tenaga kerja (Labor cost) & $1,003,585$ & 907,425 & 986,920 \\
Total biaya (Total costs) & $1,935,077$ & $1,424,907$ & $1,282,970$ \\
Penerimaan bersih (Net income) & $3,584,257$ & $2,710,116$ & $1,134,679$ \\
\hline
\end{tabular}

Sumber (Source): data primer (Primary data)

Untuk petani biasa tidak terjadi lonjakan pendapatan yang berarti dari tahun ke tahun, atau dengan kata lain pendapatan bersih yang diperoleh petani biasa relatif statis. Jika dibandingkan persentase pendapatan bersih petani koperator adalah $\mathrm{Rp} 874.141,-(32,24 \%)$ lebih besar daripada petani nonkoperator atau Rp2.449.578,- $(215,88 \%)$ lebih besar dari petani biasa. Persentase pendapatan petani nonkoperator adalah $\mathrm{Rp} 1.575 .437,-(138,84 \%)$ lebih besar dari petani biasa.

Ditinjau dari segi pendapatan bersih yang diperoleh petani, dapatlah diketahui bahwa penelitian pengembangan sistem usaha tani minapadi yang dilakukan oleh Badan Litbang Petanian telah memberikan dampak yang positif.

\section{KESIMPULAN}

1. Penelitian pengembangan sistem usaha minapadi yang telah dilaksanakan oleh Badan Litbang Pertanian ternyata memberikan dampak yang positif terhadap pendapatan bersih petani koperator.

2. Adopsi teknologi sistem usaha tani minapadi oleh masyarakat Desa Nanggerang, Binong, Kabupaten Subang berjalan dengan baik.
3. Pendapatan bersih yang terbesar diperoleh petani koperator.

4. Sistem usaha tani minapadi mengurangi penggunaan tenaga untuk penyiangan, pemupukan dan penyemprotan.

5. Sistem usaha tani minapadi lebih meningkatkan perolehan pendapatan bersih petani, dengan demikian juga meningkatkan kesejahteraan petani.

\section{DAFTAR PUSTAKA}

Oka, M.A.; D.K.S. Swastika dan W. Sudana. 1992. Impact assesment of rice fish farming system in Indonesia, CRIFC, AARD, Bogor, $42 \mathrm{p}$.

Fagi. A. M.; S. Suria Permana dan I. Syamsiah. 1991. Progress report rice fish (Indonesia) PII,I. Institute for Food Crop, Sukamandi and Reseach Institute for Freshwater Fisheries, Bogor, 74 p.

Manwan, I. dan M.A. Oka. 1990. Penelitian pengembangan teknologi tanaman pangan: pokok pemikiran dan cara pelaksanaan. Makalah disampaikan pada Rapat Kerja Puslitbang Tanaman Pangan, Maros 1-3 Juni 1990.

Syamsiah,.I.; S. Suriapermana; and A.M. Fagi. 1992. Increasing land productivity in lowland rice through rice fish culture. Sustainable agriculture for the lowland. South East Asia Sustainable Agriculture Network (SEASEN) p.125-128. 